\title{
Pengembangan Perangkat EKG 12 Lead dan Aplikasi Client-Server untuk Distribusi Data
}

\author{
SUGONDO HADIYOSO ${ }^{1}$, MUHAMMAD JULIAN ${ }^{2}$, ACHMAD RIZAL ${ }^{3}$, SUCI AULIA ${ }^{4}$
}

1,4 Fakultas Ilmu Terapan Universitas Telkom

2,3. Fakultas Teknik Elektro Universitas Telkom

Email: sugondo@telkomuniversity.ac.id

\begin{abstract}
ABSTRAK
Elektrokardiograf adalah perangkat untuk mengukur aktifitas kelistrikan jantung. Sinyal yang ditampilkan oleh perangkat elektrokardiograf adalah sinyal elektrokardiogram (EKG). Untuk monitoring ECG minimal diperlukan satu lead sementara untuk standar klinis diperlukan 12 lead. Untuk realisasi perangkat EKG 12 lead diperlukan strategi agar jumlah perangkat keras yang dibutuhkan semakin sedikit sehingga dimensi menjadi lebih kecil. Untuk mengatasi permasalahan tersebut, pada penelitian ini dirancang perangkat EKG 12 lead dengan teknik multipleksing. Kombinasi sadapan sinyal EKG 12 lead dikontrol oleh multiplekser 4051 melalui mikrokontroler secara bergantian. Data dijital hasil konversi ADC selanjutnya dikirim secara serial ke komputer server dan dapat dilihat pada komputer client yang terhubung. Hasil yang didapat menunjukkan bahawa perangkat analog telah berhasil mengakuisisi sinyal EKG dengan baik dari Lead I sampai Lead V6. Dengan waktu pensakelaran sebesar $5 \mathrm{~ms}$, sinyal tidak dapat ditampilkan secara simultan 12 lead. Sinyal dapat diakuisisi dengan baik jika waktu pensakelaran sebesar 5 detik namun seluruh sadapan sinyal EKG tidak dapat ditampilkan secara simultan.
\end{abstract}

Kata kunci: Elektrokardiograf, 12 Lead, Multipleksing, Server, Client.

\begin{abstract}
Electrocardiograph is device for measuring electrical activity of heart. Electrocardiograph displays electrocardiogram signal (ECG). For monitoring ECG, at least need one ECG lead meanwhile for standard clinical ECG need 12 lead. For realization of 12 lead ECG devices, it is need strategy to reduce number of hardware to make dimension of ECG device smaller. To solve this problem, we use multiplexing method for ECG device development. Combination of 12 lead ECG signal is controlled by the multiplexer 4051 through microcontroller sequentially. Digital data of ADC is sent serially to the server computer and can be viewed on client computer that connected to the network. From the results obtained indicate that analog devices have been successfully acquired ECG signals Lead I to Lead V6. With 5 ms switching time, the 12 lead ECG signal can not be displayed simultaneously. The signal can be acquired properly with 5 seconds switching time, but the whole of ECG signals can not be displayed simultaneously.
\end{abstract}

Keywords: Electrocardiograph, 12 Lead, Multiplexing, Server, Client. 


\section{PENDAHULUAN}

Electrocardiogram (ECG) merupakan suatu sinyal yang terbentuk sebagai hasil dari aktivitas listrik jantung. ECG diambil dengan memasang elektroda pada titik tertentu tubuh pasien. Sinyal ECG mempunyai bentuk spesifik sehingga dapat dijadikan sebagai acuan untuk menentukan kondisi kesehatan jantung oleh ahli jantung (Perez, 2002). Sinyal ECG direkam menggunakan perangkat elektrokardiograf (Tompkins, 2000).

Tingkat kematian akibat penyakit jantung sangatlah tinggi hal ini dikarenakan para penderita penyakit jantung tidak mengetahui gejalanya sejak dini. Terbatasnya fasilitas kesehatan yang memiliki perangkat rekam EKG juga menjadi penyebab hal tersebut. Harga perangkat EKG standar klinik masih tergolong mahal dan kebanyakan merupakan produk impor. Ini merupakan peluang besar untuk mengembangkan perangkat EKG dengan biaya murah sehingga dapat mengurangi ketergantungan dengan produk impor.

Pada penelitian sebelumnya telah dibangun perangkat wireless LAN ECG menggunakan ECG single lead (Rizal, 2010). Pada perkembangannya, penggunaan single lead untuk monitoring ECG tidak lagi di rekomendasikan untuk dipergunakan. Untuk keperluan monitoring ECG di rumah sakit jumlah lead yang dibutuhkan paling sedikit adalah 1 lead. Sedangkan untuk mendapatkan informasi secara lebih lengkap maka diperlukan 12 lead. Penelitian lain oleh Arif, telah direalisasikan perangkat EKG 12 sadapan dengan USB sebagai pengirim data ke komputer (Arif, 2010). Pada penelitiannya, data EKG hanya bisa dilihat pada komputer yang terhubung dengan perangkat EKG tersebut, data sinyal EKG belum dapat diakses secara luas sehingga antara perangkat EKG dan perangkat monitoring harus berada dalam satu ruangan.

Penelitian yang dikerjakan saat ini adalah merancang sistem monitoring ECG 12 lead untuk pemeriksaan pasien jantung secara lengkap. Sinyal ECG 12 lead yang didapat akan dikirimkan secara serial ke komputer server, kemudian data tersebut dapat diakses dan ditampilkan pada komputer yang terhubung dengan server tersebut. dan disimpan dalam suatu medical record sehingga dapat membantu dokter untuk mendiagnosis pasien. Sistem dirancang berbasis jaringan komputer agar bisa diakses dari jarak jauh. Untuk mengurangi jumlah penguat yang akan digunakan maka dirancang teknik multipleksing sehingga sinyal masukan dari tiap lead akan diambil secara bergantian. Dengan skema tersebut diharapkan jumlah penguat bisa direduksi dan dimensi perangkat akan bisa lebih kecil sehingga bisa mendukung mobilitas perangkat yang dirancang. Kontribusi penelitian ini adalah mengembangkan suatu perangkat EKG dengan kandungan konten lokal untuk mengurangi ketergantungan dengan produk sejenis buatan negara lain.

\section{Elektrokardiograf}

Elektrokardiogram (EKG) adalah salah satu sinyal biopotensial yang digunakan untuk menganalisis kondisi kesehatan jantung (Rizal, 2013). Perangkat yang digunakan untuk merekam sinyal biopotensial jantung adalah elektrokardiograf. Metode teknik elektrokardiografi dibagi menjadi tiga yaitu (Tompkins, 1993).

1. Monitoring EKG

Teknik ini menggunakan 1 atau 2 buah elektroda untuk memantau kondisi jantung secara kontinyu.

2. Vector cardiogram

Teknik ini menggunakan metoda sadapan segitiga Einthoven dengan 3 buah elektroda.

3. EKG Standar Klinik 
Teknik ini menggunakan 10 buah elektroda yang dipasang pada permukaan tubuh menghasilkan 12 buah sinyal sadapan jantung yang dilihat dari berbagai arah.

Pada penelitian yang dikerjakan ini adalah membuat perangkat EKG 12 lead dengan 10 elektroda menggunakan teknik multipleksing. Sadapan 12 sinyal EKG yang dihasilkan akan ditampilkan secara bergantian. Untuk mengetahui teori perancangan perangkat EKG 12 sadapan akan dijelaskan pada bagian berikut ini.

\section{EKG 12 Lead}

Setiap sadapan sinyal EKG merupakan hasil sadapan listrik dari 2 buah elektroda atau lebih yang dipasang pada permukaan tubuh. Setiap sinyal EKG memiliki orientasi vektor jantung yang berbeda-beda. Dengan EKG 12 lead ini, seluruh kondisi kelistrikan pada otot jantung dapat terlihat sehingga akan mempermudah dalam melakukan diagnosis kelainan jantung. Secara umum sadapan tersebut terdiri dari:

1. Sadapan Frontal

Pada sadapan frontal, digunakan metoda segitiga Einthoven yang menghasilkan 3 sinyal EKG yang kemudian disebut Lead I, Lead II, dan Lead III. Sadapan Lead I, elektroda positif dihubungkan dengan tangan kiri dan elektroda negatif dihubungkan dengan tangan kanan. Sadapan Lead II, elektroda positif dihubungkan dengan kaki kiri dan elektroda negatif dihubungkan dengan tangan kanan. Sadapan Lead III, eletroda positif dihubungkan dengan kaki kiri dan elektroda negatif dihubungkan dengan tangan kiri. Sebagai grounding ditambahkan satu buah elektroda yang dipasang pada kaki kanan. Lebih jelas mengenai sadapan frontal ini dapat dilihat pada Gambar 1.

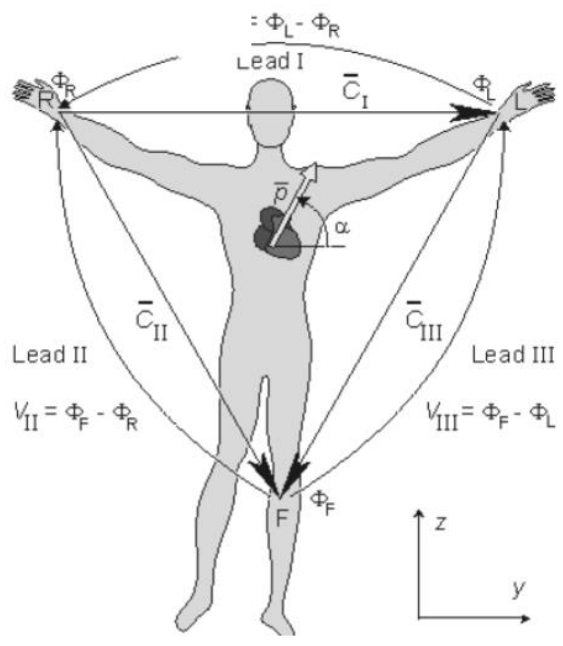

Gambar 1. Metoda Segitiga Einthoven (Aston, 1991)

Persamaan matematis untuk sadapan frontal adalah sebagai berikut.

$$
\begin{aligned}
& \text { Lead I }=\mathrm{LA}-\mathrm{RA} \\
& \text { Lead II }=\mathrm{LL}-\mathrm{RA} \\
& \text { Lead III }=\mathrm{LL}-\mathrm{LA}
\end{aligned}
$$

$$
\begin{aligned}
\text { Keterangan } \quad: \mathrm{LA} & =\text { Left Arm } \\
\mathrm{RA} & =\text { Right } \text { Arm } \\
\mathrm{LL} & =\text { Left } \text { Leg }
\end{aligned}
$$

2. Sadapan Ekstrimitas Unipolar (Augmented Limb Lead) 
Sadapan ini membandingkan tegangan pada satu titik tubuh terhadap tegangan ratarata 2 (dua) titik tubuh lainnya. Kemudian kita sebut sadapan aVR, aVL dan aVF. Maisng-masing sadapan tersebut dapat dilihat pada Gambar 2.

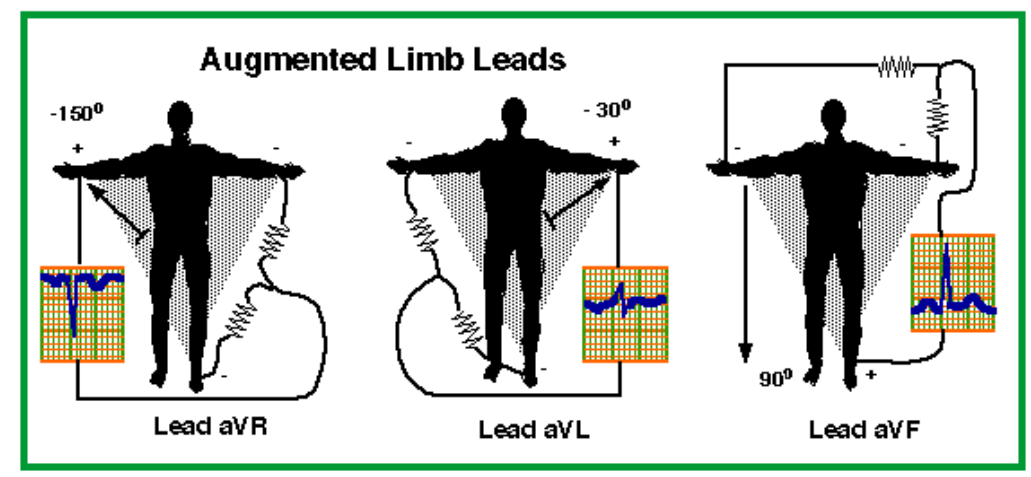

Gambar 2. Augmented Limb Lead (Penney, 2003)

Resistor yang dipasang memiliki nilai yang sama, sehingga diperoleh tegangan ratarata dari dua titik tubuh. Persamaan matematis untuk sadapan Augmented Limb Lead adalah sebagai berikut.

$$
\begin{aligned}
& \text { Lead aVR }=\mathrm{RA}-1 / 2(\mathrm{LA}+\mathrm{LL}) \\
& \text { Lead } \mathrm{aVL}=\mathrm{LA}-1 / 2(\mathrm{RA}+\mathrm{LL}) \\
& \text { Lead } \mathrm{aVF}=\mathrm{LL}-1 / 2(\mathrm{RA}+\mathrm{LA})
\end{aligned}
$$

3. Sadapan Prekordial (Precordial Lead)

Untuk mendapatkan 6 sadapan tambahan diperoleh dengan menempelkan elektroda pada bagian dada tertentu yang dibandingan dengan tegangan referensi Wilson Central Terminal (WCT). Sadapan prekordial menghasilkan Lead V1, V2, V3, V4, V5 dan V6. Gambar 3 memperlihatkan peletakan elektroda untuk sadapan prekordial dan Gambar 4 merupakan rancangan dari WCT.

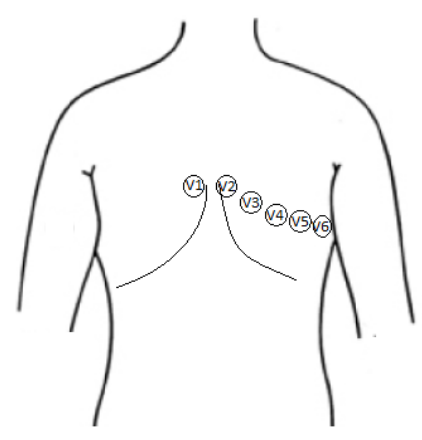

Gambar 3. Peletakan Elektroda Sadapan Prekordial 


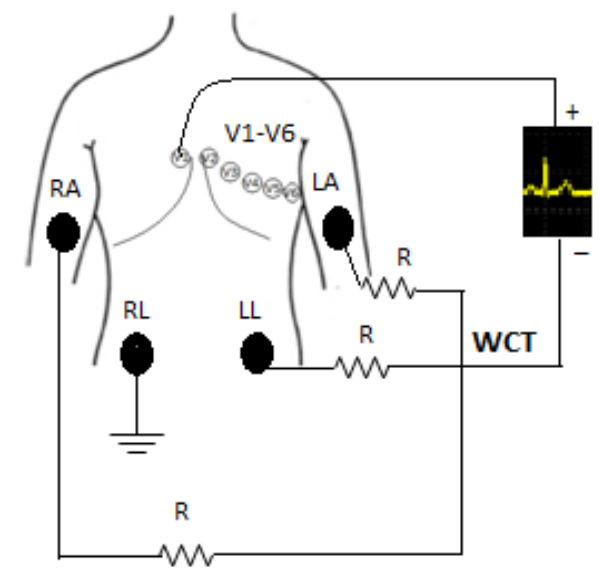

Gambar 4. Wilson Central Terminal

Persamaan matematis untuk sadapan prekordial adalah sebagai berikut.

$$
\begin{aligned}
& \text { Lead } V_{1}=V_{1}-V_{W C T} \\
& \text { Lead } V_{2}=V_{2}-V_{W C T} \\
& \text { Lead } V_{3}=V_{3}-V_{W C T} \\
& \text { Lead } V_{4}=V_{4}-V_{W C T} \\
& \text { Lead } V_{5}=V_{5}-V_{W C T} \\
& \text { Lead } V_{6}=V_{6}-V_{W C T}
\end{aligned}
$$

\section{PERANCANGAN DAN IMPLEMENTASI}

\subsection{Desain Sistem}

Gambaran umum perangkat EKG 12 lead beserta perangkat PC monitoring berbasis clientserver yang direalisasikan dapat dilihat pada Gambar 5 berikut ini.

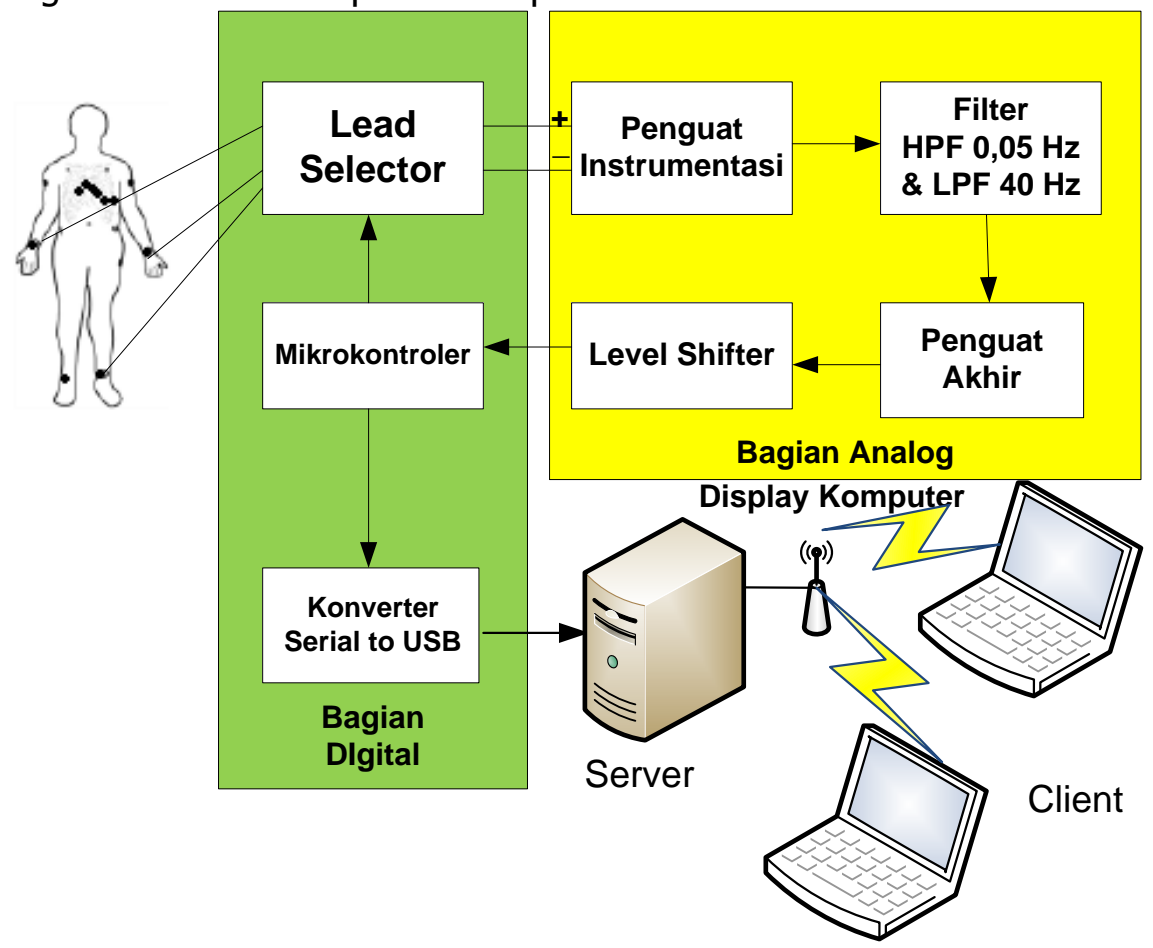

Gambar 5. Desain Sistem 
Sinyal EKG diambil melalui 10 elektroda yang dipasang pada tubuh. Rangkaian pemilih lead akan meneruskan sinyal sadapan elektroda dari lead I sampai lead V6 secara berurutan sesuai kontrol yang diberikan oleh mikrokontroler. Selanjutnya sinyal EKG dengan magnitude yang kecil $(0,5-3 \mathrm{mV})$ dan noise yang relatif besar dikuatkan oleh rangkaian penguat instrumentasi. Untuk menghilangkan noise yang ditimbulkan oleh gerakan tubuh dan menjaga sinyal EKG pada frekuensi kerjanya maka dilewatkan pada rangkaian filter HPF 0,05 $\mathrm{Hz}$ dan LPF $40 \mathrm{~Hz}$. Selanjutnya sinyal dikuatkan kembali menggunakan penguat operasional untuk memaksimalkan pembacaan oleh ADC. Agar seluruh komponen sinyal berada pada level positif maka diperlukan sebuah rangkaian penggeser tegangan untuk melakukan fungsi tersebut. Sinyal analog EKG selanjutnya dilakukan dijitalisasi oleh mikrokontroler kemudian dikirim secara serial ke perangkat komputer server agar dapat diakses oleh komputer client. Pada komputer client yang sudah ter-install program aplikasi dapat dilihat representasi grafik sinyal EKG dijital.

\subsection{Implementasi Hardware}

Implementasi perangkat keras yang terdiri dari implementasi pemilih lead, rangkaian Wilson Central Terminal (WCT), penguat instrumentasi, filter, penguat akhir, level shifter, mikrokontroler.

\subsubsection{Implementasi Rangkaian Pemilih Lead (Lead Selector)}

Rangkaian ini berfungsi untuk meneruskan sadapan sinyal EKG dari tubuh yang dikontrol oleh mikrokontroler. Terdiri dari 3 (tiga) buah IC multiplexer 4051 yang disusun sedemikian rupa agar dapat meneruskan sinyal dari lead I sampai dengan lead V6 secara bergantian.

IC 4051 memiliki 8 pin masukan sinyal dengan 3 buah pin kontrol untuk mengatur sinyal mana yang akan diteruskan. Kontrol tersebut dilakukan dengan memberikan logika 000-111. Sebagai contoh jika diberikan kontrol 000 maka akan meneruskan sinyal dari pin masukan 0 , jika diberikan logika 001 maka akan meneruskan sinyal dari pin masukan 1 dan seterusnya. Dari susunan tiga buah multiplekser ini, memberikan dua buah pin luaran yang diteruskan pada rangkaian penguat instrumentasi.

Dengan memperhatikan persamaan matematis EKG 12 lead yang telah dipaparkan pada bagian sebelumnya, tanda positif berarti sinyal diteruskan pada pin masukan positif penguat instrumentasi dan tanda negatif berarti sinyal diteruskan menuju pin masukan negatif penguat instrumentasi. Gambar 6 berikut menunjutkan susunan dari IC 4051. Logika kontrol yang diberikan pada setiap IC dapat dilihat pada Tabel 1. 


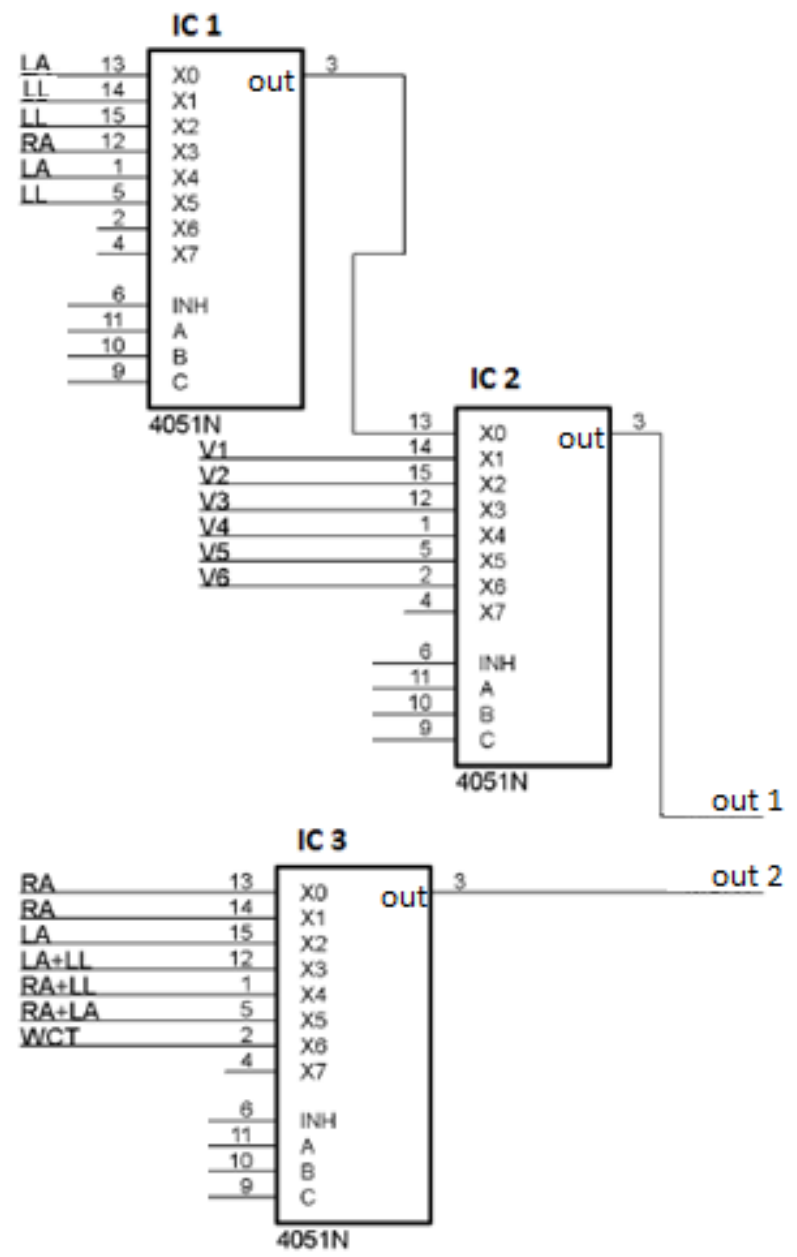

Gambar 6. Rangkaian Pemilih Lead

Tabel 1. Tabel kebenaran kontrol selektor

\begin{tabular}{|c|c|c|c|}
\hline Lead & IC 1 & IC 2 & IC 3 \\
\hline I & 000 & 000 & 000 \\
\hline II & 001 & 000 & 000 \\
\hline III & 010 & 000 & 010 \\
\hline aVR & 011 & 000 & 011 \\
\hline aVL & 000 & 000 & 100 \\
\hline aVF & 010 & 000 & 101 \\
\hline V1 & XXX & 001 & 110 \\
\hline V2 & XXX & 010 & 110 \\
\hline V3 & XXX & 011 & 110 \\
\hline V4 & XXX & 100 & 110 \\
\hline V5 & XXX & 101 & 110 \\
\hline V6 & XXX & 110 & 110 \\
\hline
\end{tabular}

\subsubsection{Rangkaian Wilson Central Terminal(WCT)}

Rangkaian WCT merupakan rangkaian untuk mendapatkan tegangan referensi dari tiga titik tubuh yang berbeda untuk menghasilkan tegangan rata-rata antara tiga titik tubuh tersebut. 
Tiga titik yang dimaksud adalah tangan kanan, tangan kiri dan kaki kiri. WCT terhubung langsung dengan elektroda dan rangkaian pemilih lead. Rangkaian WCT dapat dilihat pada Gambar 7 berikut.

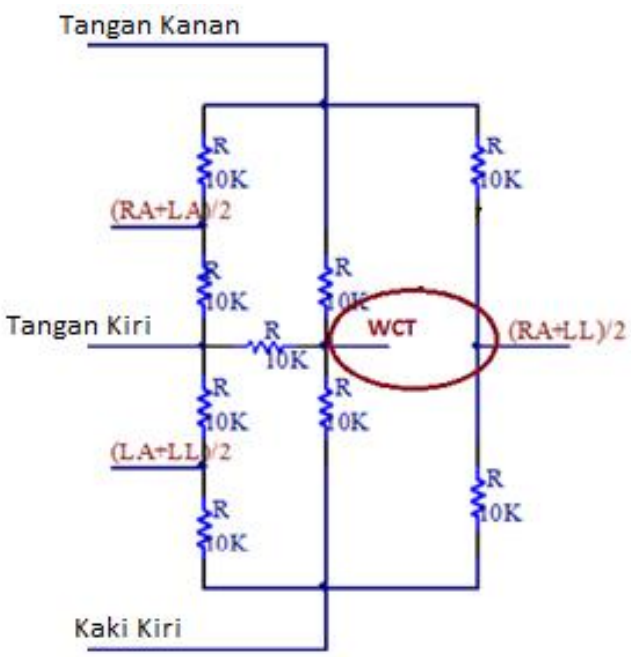

\section{Gambar 7. Rangkaian Wilson Central Terminal}

\subsubsection{Rangkaian Penguat Instrumentasi}

Penguat instrumentasi berfungsi untuk menguatkan sinyal dengan amplitudo yang sangat rendah yang bercampur dengan noise yang relatif besar. Penguat instrumentasi merupakan susunan dari penguat operasional. Namun dalam penelitian ini digunakan IC INA118 sebagai penguat instrumentasi. Dengan mempertimbangkan nilai CMRR yang tinggi yang dimiliki oleh IC tersebut.

Masukan penguat instrumentasi ini bersumber dari 2 buah luaran rangkaian pemilih lead. Dimana output 1 dihubungkan dengan pin masukan positif dan output 2 dihubungkan dengan pin masukan negatif. Gain diatur dengan mengubah nilai resistor RG, pada penelitian ini RG yang dgunakan sebesar 5,6K $\Omega$ didapatkan penguatan sebesar \pm 10 kali. Rangkaian penguat instrumentasi dapat dilihat pada Gambar 8.

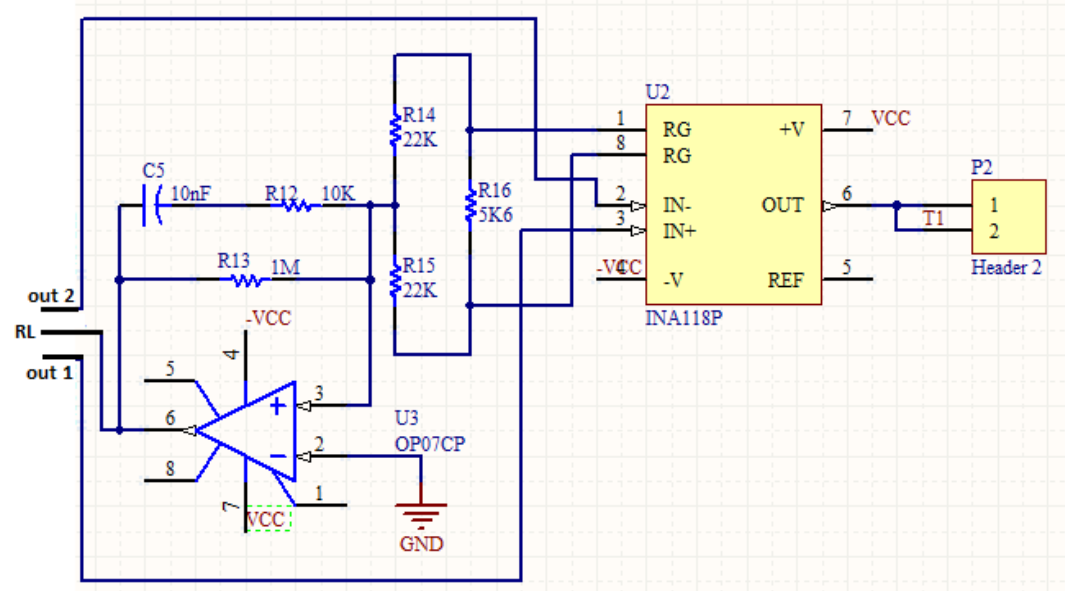

\subsubsection{Rangkaian Filter}

Gambar 8. Penguat Instrumentasi

Filter digunakan untuk mengurangi noise yang dihasilkan oleh gerakan tubuh dan menjaga sinyal EKG pada frekuensi kerjanya. Filter yang direalisasikan adalah filter HPF dengan cut off $0,05 \mathrm{~Hz}$ dan LPF dengan cut off $40 \mathrm{~Hz}$. Rangkaian filter tersebut dapat dilihat pada Gambar 9 dan Gambar 10. 


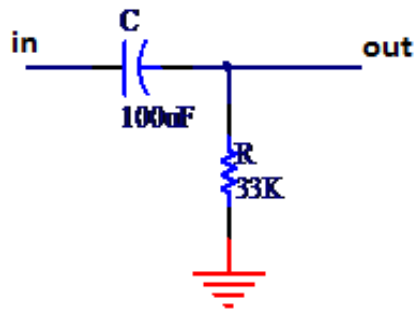

Gambar 9. HPF Pasif 0,05 Hz

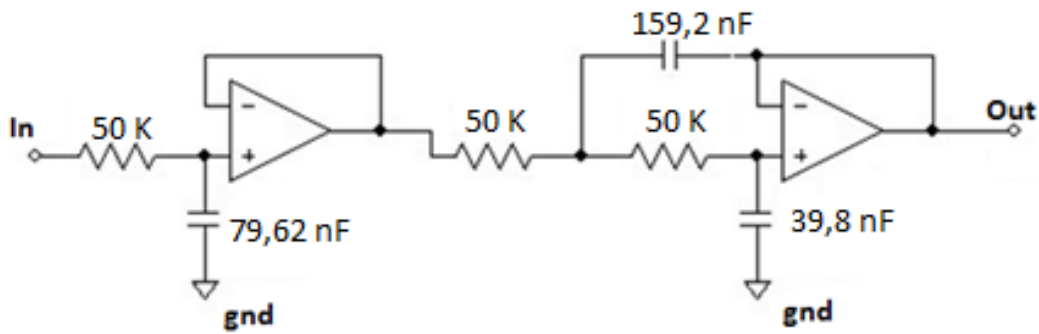

Gambar 10. LPF Aktif $40 \mathrm{~Hz}$ Orde 2 topologi Sallen Key

\subsubsection{Rangkaian Penguat Akhir dan Level Shifter}

Sinyal EKG luaran penguat instrumentasi masih memiliki nilai tegangan dengan orde mili volt. Untuk memperkecil kesalahan pembacaan ADC maka sinyal tersebut perlu dikuatkan dengan besar penguatan \pm 100 kali menggunakan penguat operasional. Selanjutnya untuk memastikan seluruh komponen sinyal EKG berada pada level tegangan positif diperlukan adanya rangkaian penggeser tegangan. Rangkaian tersebut, masing-masing dapat dilihat pada Gambar 11 dan Gambar 12.

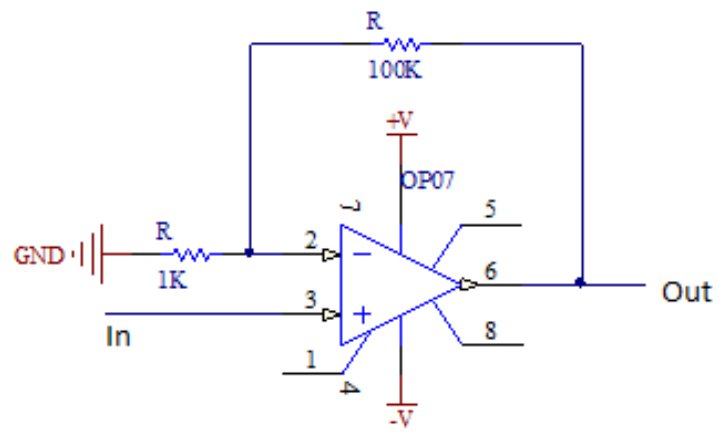

Gambar 11. Penguat Akhir

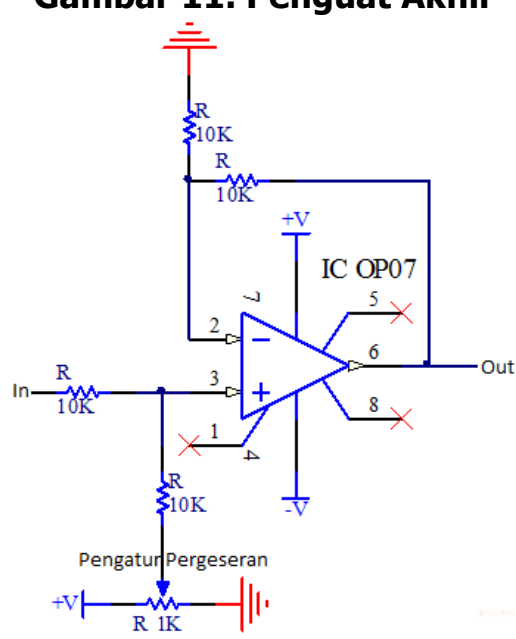

Gambar 12. Level Shifter 


\subsubsection{Mikrokontroler}

Pada rancangan EKG 12 lead ini menggunakan mikrokontroler ATMega 16 sebagai pengatur kerja switching dari rangkaian pemilih lead, melakukan proses konversi data analog dari sinyal EKG menjadi data digital dan mengirimkan data sinyal digital EKG ke komputer melalui serial komunikasi via USB to RS232. Skematik sistem minimum mikrokontroler ditunjukkan pada Gambar 13.

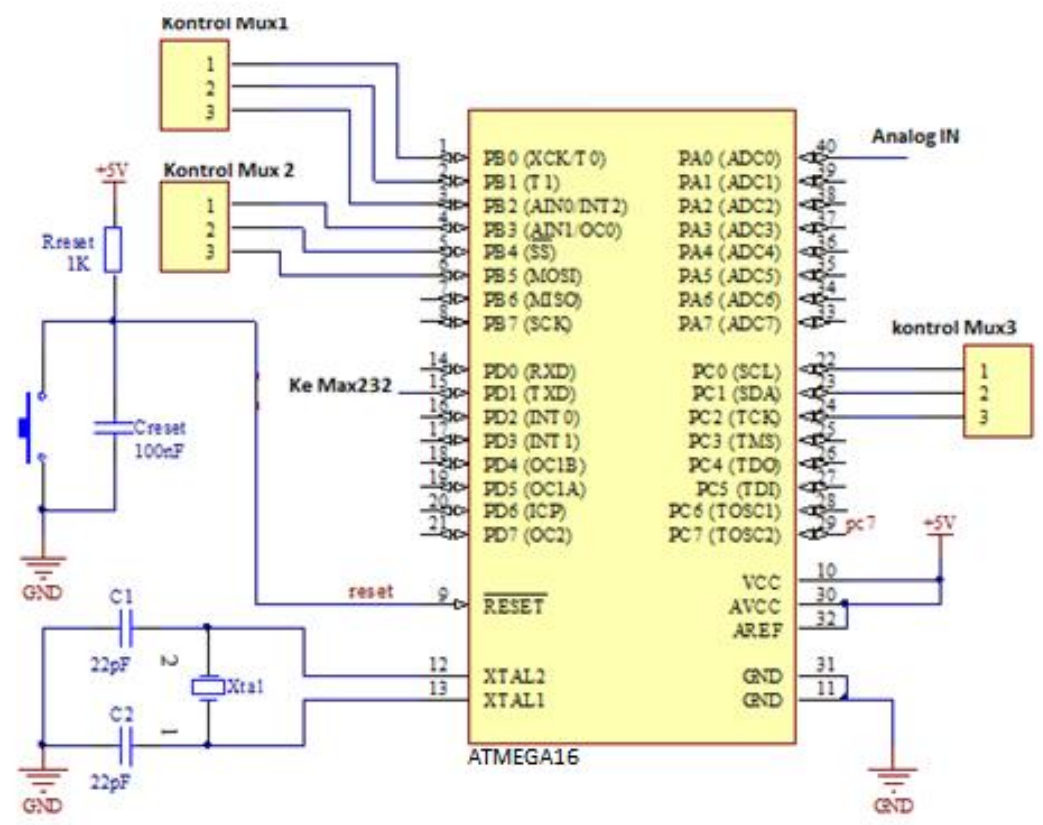

Gambar 13. Sistem Minimum Mikrokontroler

\subsection{Perancangan Program Aplikasi}

Aplikasi Pemrograman pada komputer dirancang menggunakan software Microsoft Visual Studio 2010 C\#. Program ini ditunjukan untuk menguji coba sistem rangkaian digital pada perancangan EKG 12 lead dan pengujian pengiriman data. Program ini dapat menampilkan data ADC yang dikirim dari mikrokontroler dan proses distribusi data EKG dijital dilakukan secara wireless oleh akses point dengan metode Server to Client. Komputer client akan tehubung dengan komputer server dengan cara mengakses PORT dan IP pada server.

\section{HASIL DAN PEMBAHASAN}

Pengujian yang dilakukan meliputi pengujian performansi perangkat aukisisi sinyal EKG dan pengujian aplikasi client-server data EKG dijital.

\subsection{Pengujian Analog Front End EKG 12 Lead}

Pengujian perangkat analog akuisisi sinyal EKG dilakukan untuk mengetahui keberhasilan perangkat dalam mengambil sinyal lead I, II, III, AVL, AVR, AVF, V1, V2, V3, V4, V5 dan V6.. Hasil pengujian bagian filter dan penguat, diambil pada salah satu lead yaitu lead II (Gambar 14). Berikut adalah 12 sinyal EKG hasil akuisisi yang ditampilkan pada layar osiloskop dapat dilihat pada Gambar 15 dan 16. 
Pengembangan Perangkat EKG 12 Lead dan Aplikasi Client-Server untuk Distribusi Data

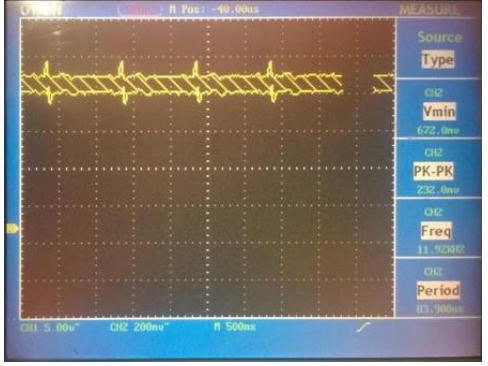

(a)

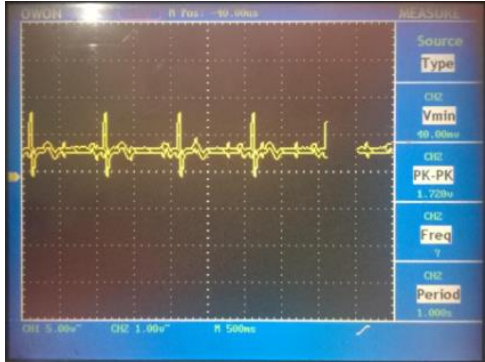

(b)

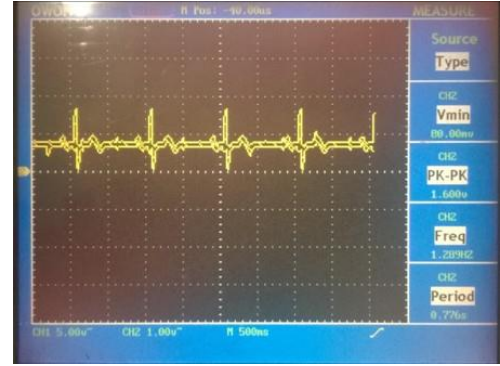

(c)

Gambar 14. Output Analog Lead II (a) Penguat (b) Filter HPF (c) Filter LPF

Dari Gambar 14, sinyal luaran penguat instrumentasi sinyal EKG masih bercampur dengan noise namun bentuk dasar sinyal EKG sudah terlihat. Setelah dilewatkan pada rangkaian filter $(0,05-40 \mathrm{~Hz})$, noise dapat direduksi sehingga QRS kompleks EKG terlihat jelas.

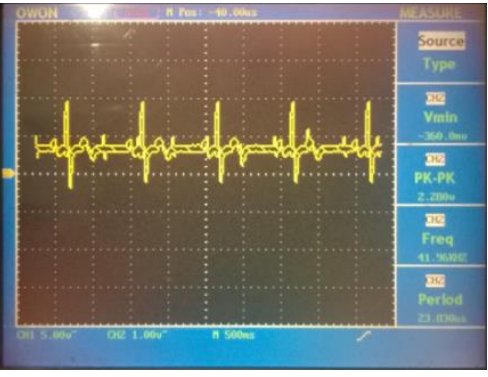

(a)

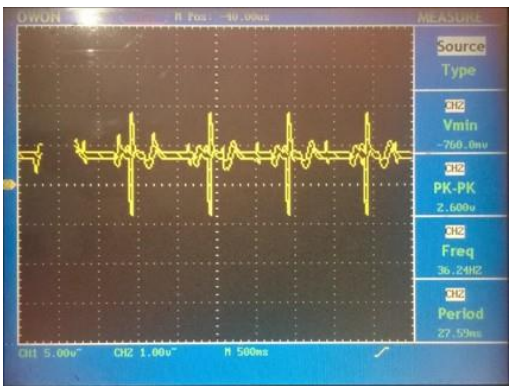

(d)

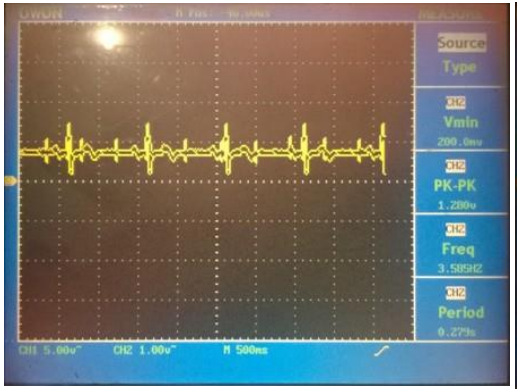

(g)

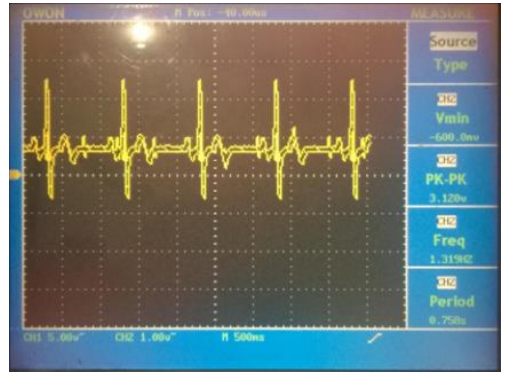

(b)

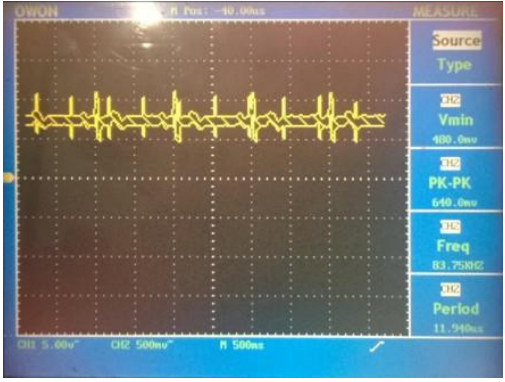

(e)

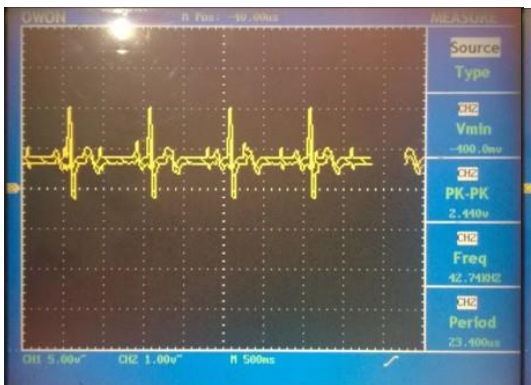

(h)

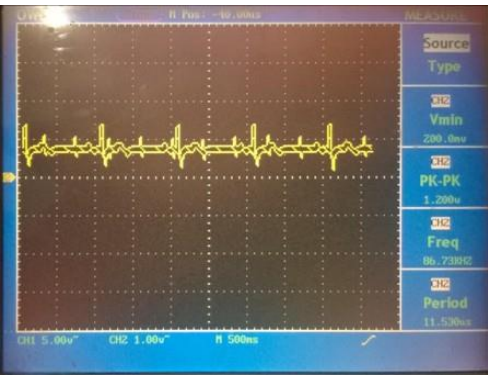

(c)

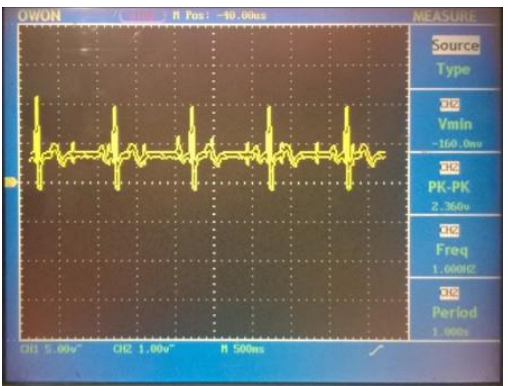

(f)

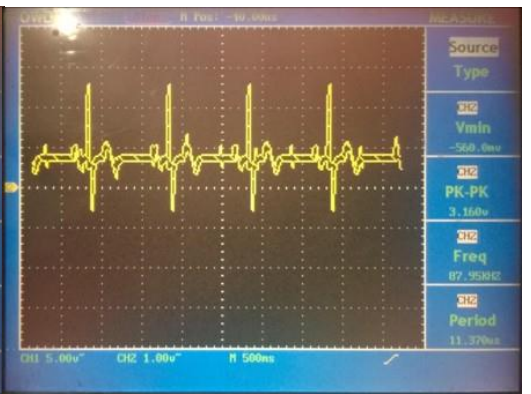

(i)

Gambar 15. Hasil Sadapan Lead (a) I, (b) II, (c) III, (d) AVL, (e) AVR, (f) AVF, (g) V1, (h) V2, (i) V3 


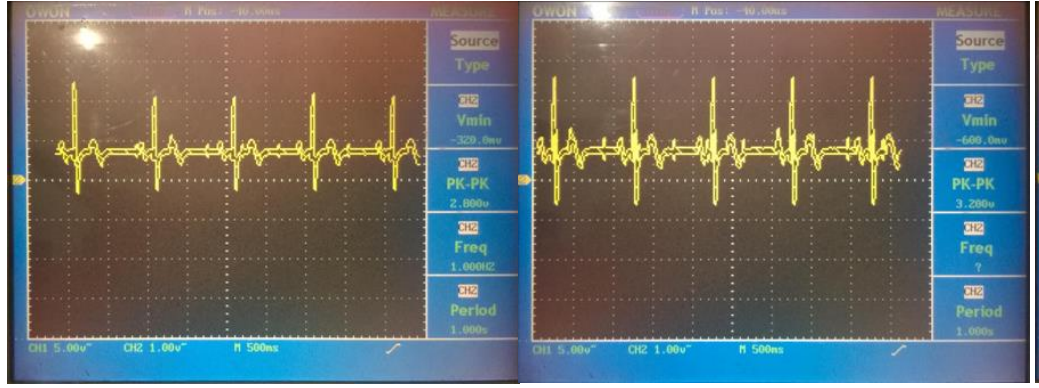

(a) (b)

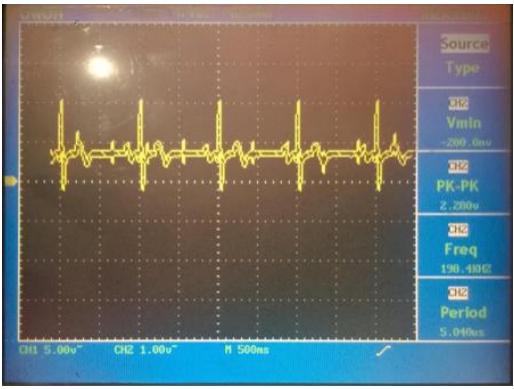

(c)

Gambar 16. Hasil Sadapan Lead (a) V4, (b) V5, (c) V6

Dari Gambar 15 dan 16, perangkat AFE EKG dapat melakukan akuisisi 12 sinyal EKG dengan baik. Seluruh rangkaian analog bekerja sesuai dengan rancangan awal sehingga sinyal EKG hasil sadapan terlihat jelas dengan noise yang relatif kecil.

\subsection{Pengujian Aplikasi Client-Server}

Aplikasi server berfungsi untuk menerima data serial sinyal EKG yang dikirim oleh perangkat EKG, kemudian meneruskan data tersebut ketika terdapat komputer client yang melakukan request. Koneksi client dapat dilakukan dengan mengakses IP server pada jaringan LAN maupun wifi. Pada komputer client, data disimpan dalam bentuk file text kemudian diplot dalam bentuk grafik menggunakan microsoft excel. Hasil pengujian data yang diterima pada terminal server dan client dapat dilihat pada Gambar 17.

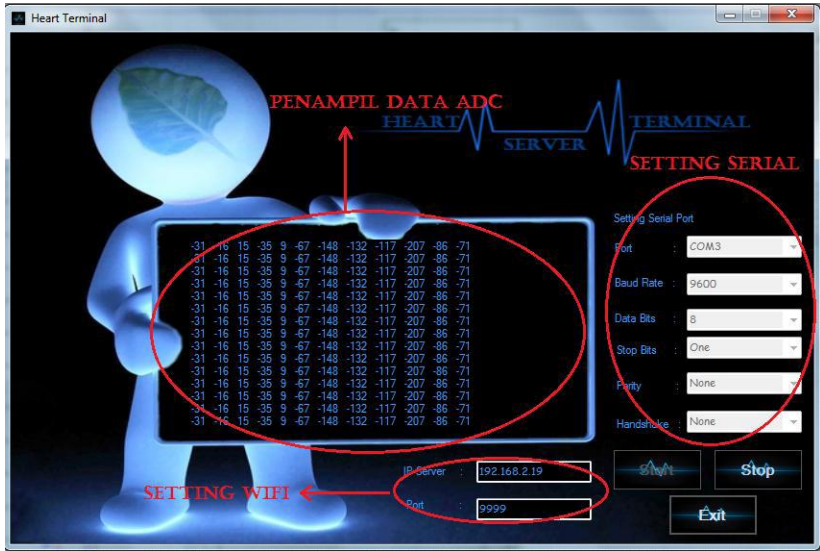

(a)

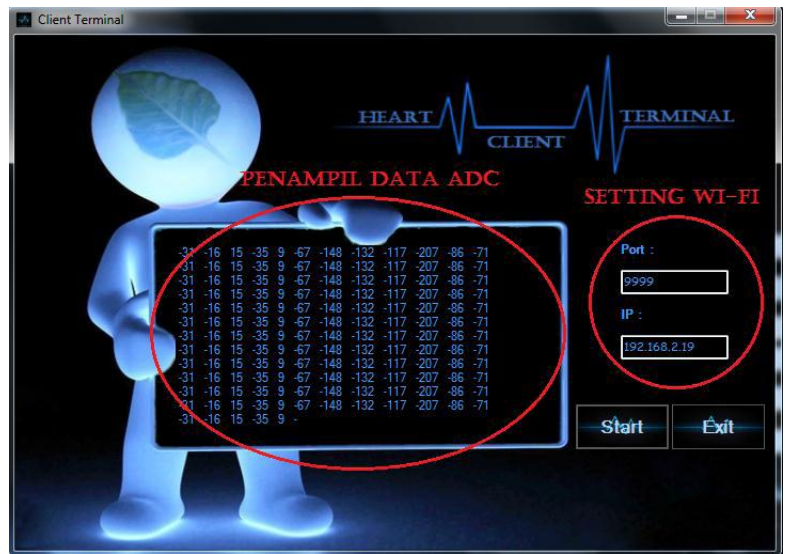

(b)

Gambar 17. Aplikasi Penerima Data pada Server dan Client

Berdasarkan hasil pengujian yang ditunjukkan pada Gambar 16, aplikasi terminal server dapat menerima data sinyal EKG berupa data integer yang ditampilkan pada kolom data. Bersamaan dengan itu, client dapat mengakses dan meminta data tersebut kepada server. Dari gambar dapat dilihat bahwa data yang diterima client sama dengan data yang berada di server.

\subsection{Pengujian Perfomansi Sistem Secara Keseluruhan}

Tujuan utama pada penelitian ini adalah akuisisi EKG 12 lead dan menampilkannya secara simultan. Pada desain rangkaian awal ini, sinyal EKG dilewatkan pada multiplekser dengan pengaturan yang dilakukan oleh mikrokontroler. Mikrokontroler diprogram untuk mengontrol 
perubahan switch dengan jeda waktu $1 \mathrm{~ms}, 2 \mathrm{~ms}$ dan $5 \mathrm{~ms}$ untuk melakukan pensaklaran setiap lead kemudian ADC melakukan konversi sinyal setiap lead tersebut. Dengan jeda waktu yang relatif kecil diharapkan sinyal dapat ditampilkan secara simultan.

Untuk mempermudah program aplikasi memisahkan data dari setiap lead dibuatlah suatu rekayasa program dengan menambahkan karakter spasi sebagai pemisah antara data lead yang satu dengan yang lain, kemudian hasilnya dapat dilihat melalui aplikasi hyper terminal. Hasil pengujian dapat dilihat pada Gambar 18 dan Gambar 19.

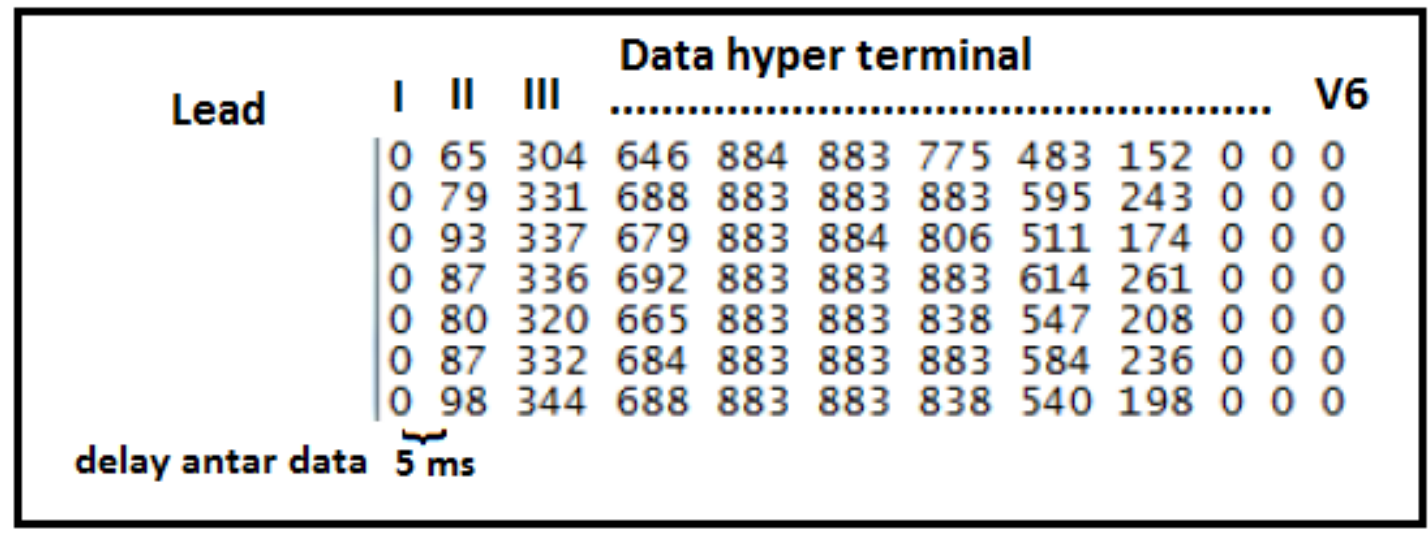

Gambar 18. Data EKG Dijital yang Tampil pada Hyper Terminal

Dari Gambar 18, dapat diketahui bahwa ADC dapat melakukan konversi sinyal analog setiap pensakelaran oleh multiplexer dan data dijital hasil konversi dikirim dengan format sesuai dengan rancangan. Data dari masing-masing sadapan dipisahkan oleh spasi. Pindah baris menandakan pembacaan data dimulai kembali dari lead I.

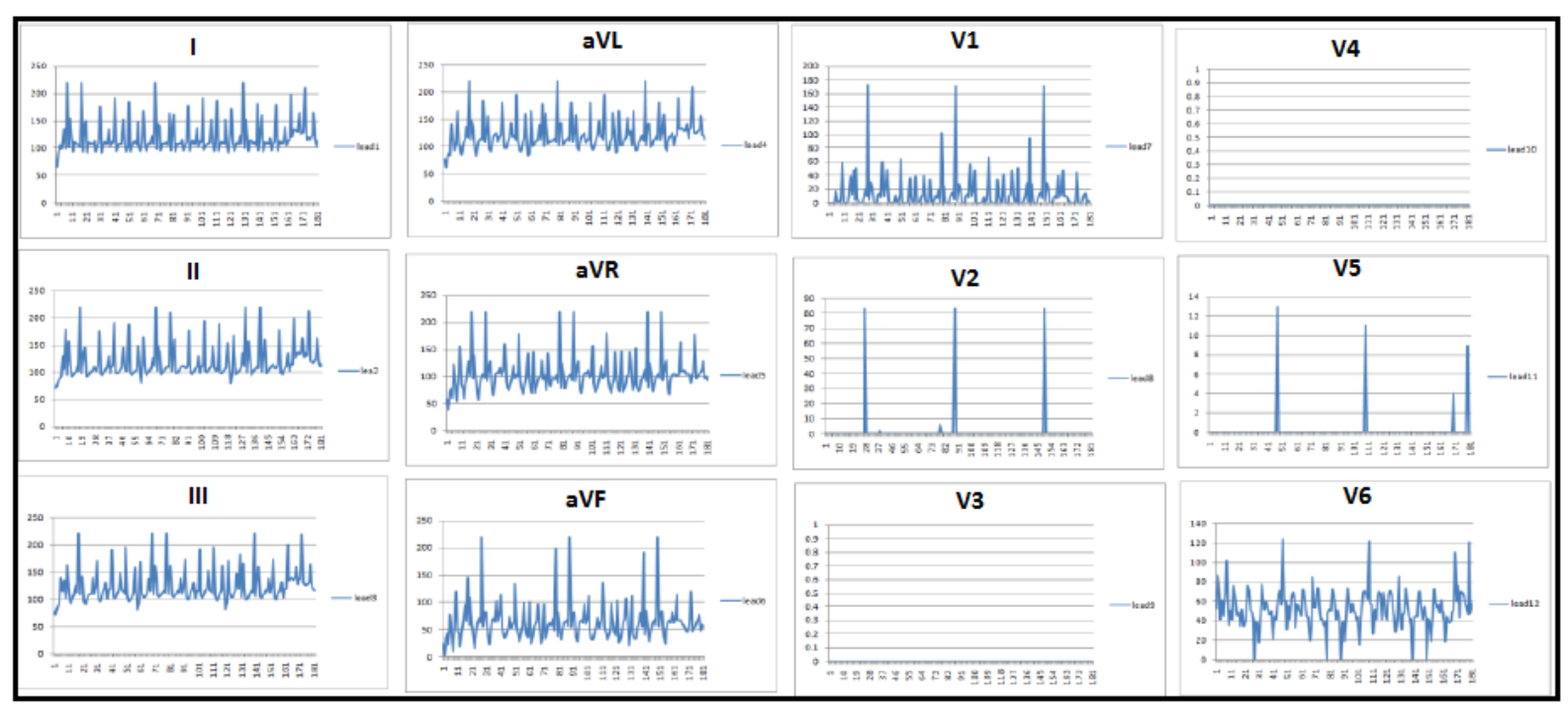

Gambar 19. Plot Grafik Data EKG 12 Lead dengan Delay Multiplekser 5ms

Dari hasil di atas diperoleh kesimpulan, dengan rancangan awal ini sinyal 12 sadapan sinyal EKG tidak dapat ditampilkan dengan baik dikarenakan waktu pensakelaran yang terlalu cepat mengakibatkan sinyal akuisisi menjadi rusak. Kecepatan penjalaran sinyal elektris pada rangkaian tidak sebanding dengan kecepatan switch.

Untuk membuktikan kesimpulan tersebut, pengujian juga dilakukan dengan jeda pensakelaran selama 5 detik. Berikut ini adalah gambar hasil pengujian tersebut. 


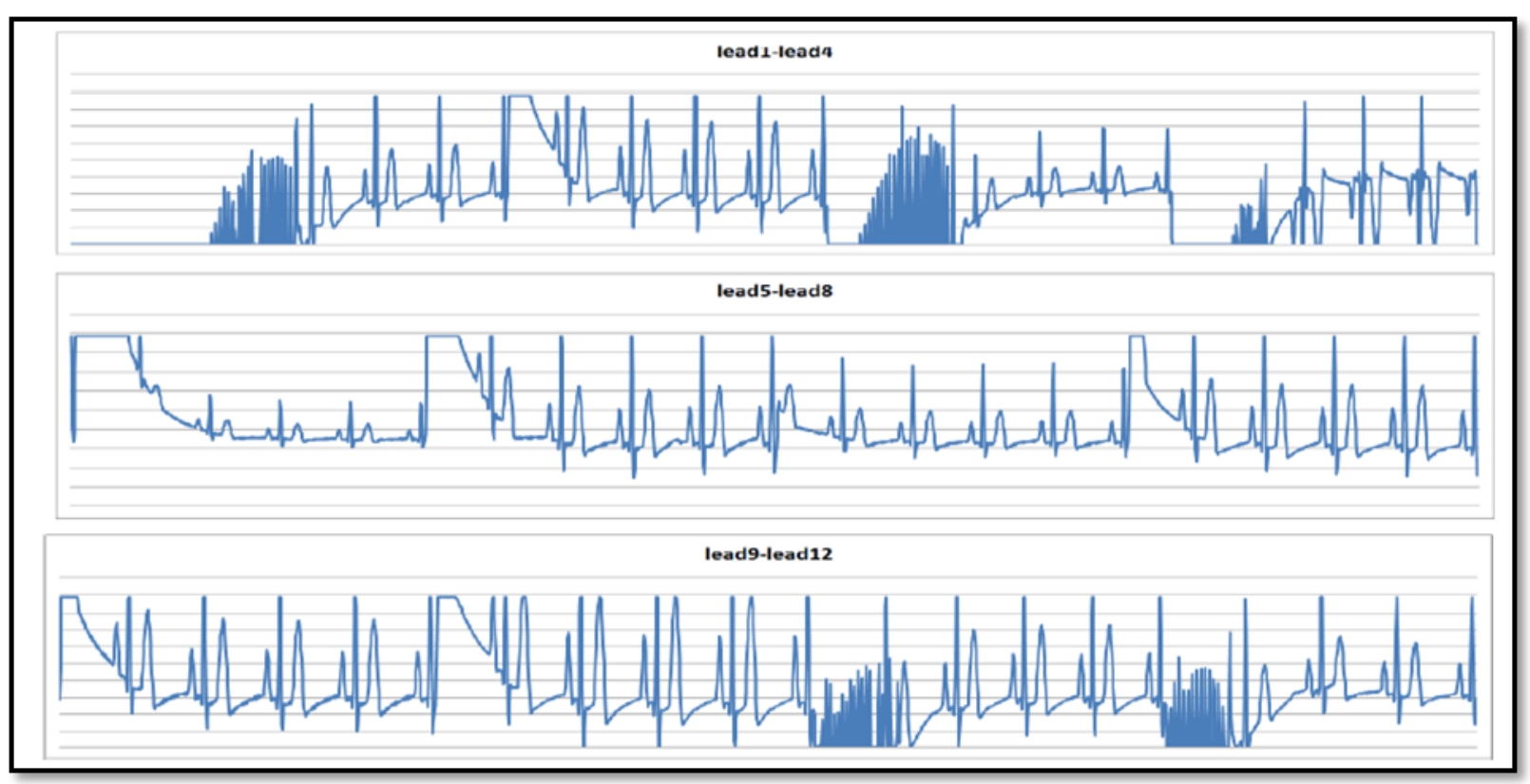

Gambar 20. 12 Sinyal EKG dengan Pensaklaran 5 detik

Pada skenario ini, 12 sinyal sadapan EKG terlihat jelas, namun tidak dapat ditampilkan secara simultan dikarenakan delay perpindahan yang terlalu besar. Dari hasil pengujian ini seluruh sadapan sinyal EKG akan ditampilkan secara bergantian setiap 5 detik. Selain itu, akibat dari proses pensakelaran multiplekser akan menimbulkan sinyal transisi berupa noise pada selang waktu antara lead yang satu dengan yang lainnya. Untuk dapat melihat data setiap lead dengan durasi yang lebih panjang maka delay pensakelaran dapat diperbesar.

\section{KESIMPULAN}

Dari hasil perancangan, realisasi dan pengujian perangkat EKG 12 lead berikut aplikasi clientserver untuk distribusi data, diperoleh kesimpulan sebagai berikut.

1. Penelitian ini telah berhasil mengimplementasikan perangkat analog untuk akuisisi sinyal EKG 12 lead.

2. Dengan teknik multiplexing, dibutuhkan satu kanal ADC untuk mengonversi 12 sinyal EKG.

3. Dengan waktu pensaklaran $1 \mathrm{~ms}, 2 \mathrm{~ms}$ dan $5 \mathrm{~ms}$ sinyal dapat ditampilkan secara bersamaan namun bentuk sinyal EKG menjadi tidak terlihat.

4. Dua belas sinyal sadapan EKG dapat terlihat jelas pada setiap lead-nya jika waktu pen-saklaran $\geq 5$ detik. Pada skenario ini sinyal EKG dari masing-masing lead ditampilkan secara berurutan (tidak simultan).

5. Aplikasi pada server dapat menerima data EKG dengan baik dan dapat mendistribusikan data tersebut ke komputer client yang terhubung dalam satu jaringan. 


\section{DAFTAR RUJUKAN}

R, Perez.(2002). Design of medical electronic devices. San Diego: Academic Press.

W. J. Tompkins.(2000). "Electrocardiography," in Biomedical Digital Signal Processing, Ed. New Jersey: Prentice Hall. pp. 24-54.

A. Rizal and Jondri.(2010). "Wireless LAN Electrocardiograph ( ECG )," in Konferensi Nasional Sistem dan Informatika 2010.pp. 15-20.

Widodo, Arif.(2010). Sistem Akuisisi ECG Menggunakan USB Untuk Deteksi Aritmia. Proceedings Seminar Tugas Akhir Jurusan Teknik Elektro FTI - ITS Surabaya

Rizal, Achmad.(2013). Instrumentasi Biomedis. Bandung: Graha Medika.

W. J. Tompkins.(1993). Biomedical Signal Processing. New Jersey: Prentice Hall.

R. Aston.(1991). Principles of Biomedical Instrumentation and Measurement. New York: MacMillan Publishing Co.

Penney, D. (2003). Electrocardiography. Dipetik 22 Agustus 2015 dari http://www.coheadquarters.com/PennLibr/MyPhysiology/lect0/figecg12.htm 